\title{
Development of Cyber Resilient Capability Maturity Model for Cloud Computing Services
}

\author{
Ekkachat Baikloy, Prasong Praneetpolgrang, Nivet Jirawichitchai \\ School of Information Technology, Sripatum University, Bangkok, Thailand
}

\begin{abstract}
The research objectives were: 1) to develop cyber resilient model, 2) to develop the cyber resilient capability maturity model and 3) to develop self-assessment model for cyber resilient capability of cloud computing services which are qualitative and applicative research. Referring to the cybersecurity concept from National Institute of Standards and Technology (NIST) from the in-depth interview, focusgroup discussion was developed with cybersecurity experts and data collection from cloud services providers. It was found that trend of cyber-attacks was violent with smarter method. The authors had synthesized the concept of cyber resilient capability maturity model for cloud computing services including developed application for cloud services providers to evaluate their organization in order to improve the better cybersecurity level in cloud computing services and the cyber resilient capability maturity model in the future.
\end{abstract}

Keywords - Cloud Computing Services, Cloud Service Provider, Cyber Resilience, Capability Maturity Model.

\section{Introduction}

Digital technology especially cloud computing services has played the key role in improving and enhancing organization and business sector efficiency. Most of the business sectors try to adjust

DOI: $10.18421 /$ TEM93-11

https://doi.org/10.18421/TEM93-11

Corresponding author: Ekkachat Baikloy, Ekkachat Baikloy, School of Information Technology, Sripatum University, Bangkok, Thailand.

Email: mrekkachat@hotmail.com

Received: 30 April 2020.

Revised: 24 July 2020.

Accepted: 30 July 2020.

Published: 28 August 2020.

(c) BY-NC-ND C 2020 Ekkachat Baikloy, Prasong Praneetpolgrang \& Nivet Jirawichitchai; published by UIKTEN. This work is licensed under the Creative Commons Attribution-NonCommercial-NoDerivs 4.0 License.

The article is published with Open Access at www.temjournal.com working pattern to be on cloud platform saving working cost with more effectiveness. Most importantly, the business will be flexible by making additional benefit of the business stakeholders. Moreover, what needs to be considered together with cybersecurity is cloud computing services.

Nowadays, there are several cloud service providers or agencies, who are the group of users or business clients that consider using cloud computing service, but there is still doubt on risk and cybersecurity of the service [1]. Therefore, the authors were interested in the study on cyber resilient capability and the resilient method evaluation cyber related for cloud computing services and understand the level of cybersecurity of the service provider for business costumer group making the service providers worked safely and sustainably. Moreover, cloud services provider and the users have guideline or reference in practicing creating convenience and benefit for the related in every sector in business process. "Service Provider" means cloud services provider and "user" means the users of electronic transaction with cloud.

\section{Related Work}

\subsection{Cloud Computing Services}

Cloud computing refers to a pattern of computing conveniently sharing resources through network as demand from everywhere. The users do not have to manage the resource by themselves [2]. The examples of resources are network, server, storage capacity, applied software and cloud services or cloud computing Services referred to the services through cloud computing system according to main service type. The users are able to access to internet system through various electronic tools such as computer, smartphone or tablet helping them working flexibly. Types of main Service are Infrastructure as a Service (IaaS), Platform as a Service (PaaS), and Software as a Service (SaaS).

Apart from various services types, cloud services can be divided according to working types into 3 types: 1. Private Cloud, 2. Public Cloud, and 3. Hybrid Cloud which are similar to the users having their own computer system connecting to data center 
of the service provider. The data center needs to be under standard system with high security because trustworthiness and the confidence in the whole system effectiveness have to be built up for the users.

\subsection{Cloud Services Standard of Practice}

2.2.1 Cloud Services Standard of Practice by Engineering Institute of Thailand is under H.M. The King's Patronage mentioning cloud computing service as the new concept of nowadays application digital technology with technology resource management system or modern and flexible digital technology is established in order to support various types of businesses according to the practice of service provider and cloud users in Thailand in term of data safety and the preparation in the same standard with the regulation as follows: 1. Open standard system and working cooperation of data, program and hardware, 2. Program and data transportation from one system to another, and 3. Access right and data connection management [2].

2.2.2 Cloud Security Alliance (CSA) is the organization launching the regulation with the objective to ensure the user about the service with the cloud system security and safety control under the evaluation and guarantee in the name of CSA-STAR (Cloud Security Alliance - Security, Trust \& Assurance Registry) CSA Star. It is the standard basically from ISO/IE27001 (ISMS) together with Cloud Control Matrix (CCM) and Maturity Model. ISMS focus on confidential, integrity, and availability. The guarantee is divided into 3 types 1. STAR Entry - Self Assessment: with internal organization evaluation with CSA Consensus Assessment Initiative (CAI) or Cloud Control Matrix (CCM), 2. STAR Certification/Attestation: needs to pass ISO ISO27001 or AICPA SOC2 from outsource company,and 3. STAR Continuous: needs to be constantly tested and evaluated the safety of Cloud system.

2.2.3 The Statement on Standards for Attestation Engagement (SSAE18) was the report of the practice according to the rule and regulation of the service related to organization including cloud. This report is called Service Organization Controls (SOC) divided into 3 types - SOC1 is the financial report, SOC2 is the report on evaluation of organizational technology safety control efficiency with principal of trust services composed of 5 topics which are safety, ready-to-use condition maintenance, accuracy maintenance of working process, confidentiality and personal information maintenance. SOC 3 is the evaluation report only in safety security, ready-to-use condition maintenance and secrecy that can be revealed to public.
2.2.4 ISO/IEC27001 is the international standard in Information Security Management Systems ISMS with the practice from the beginning system, process, revise and constant improvement in accordance with PDCA (Plan-Do-Check-Act)

2.2.5 ISO/IEC ISO 27002 refers to the 133 topics of obligation of Information Security Management. Both ISO/IEC 27001 and ISO/IEC 27002 focus on "management system" with the obligation of Information Security Management in order to support the standard including the emergency plan and sustaining to constant business ability [3].

2.2.6 ISO/IEC 27017 is international standard for cloud services security management taking some information from ISO 27002 with the addition of cloud computing services set to control, and it is responsible for sharing information security management between cloud services provider and user as follows: 1. Cloud users have to be protected and gain the right to access the service in the environment similar as other users, 2. Operation $\log$ and logs in cloud services system need to be suitably managed, 3. The risk management about cloud information security management need to include the service guarantee agreement (SLA) between service provider and user in term of personal information security management in the system.

2.2.7 ISO/IEC 27018 is the guideline for public cloud service provider especially in Personal Identifiable Information, which means the data identifying users and connects to any person in the network such as name, address, phone number or email.

2.2.8 ISO/IEC 27032:2012 the extension of ISO 27001 about Confidentiality, Integrity and Availability with cyber property security such as hardware, software, data, service including virtual assets such as reputation.

2.2.9 ISO/IEC 20000-1:2011 service mind standard (SMS) is the regulation of Service Provider in planning, improving, processing, following, maintenance and improving SMS.

2.2.10 ISO 22301:2012 is Business Continuity Management Systems helping each organization plan to systemically face with types of disasters especially the cyber-attack.

2.2.11 ISO29100:2011 Privacy Framework is the regulation protecting personal information referring to any information relating to a person both directly and indirectly or in practice causing the seeking for a person or in the form that can be accessed or processed.

2.2.12 ISO 31000:2009 is the organizational risk management with the principal and guideline including this standard by making the organization able to analyze the risk and evaluate internal risk. 


\subsection{Cybersecurity Concept and Cyber Resilience}

2.3.1 NIST Cybersecurity version 1.1 shows 5 topics of cybersecurity including: 1 . Risk identify on resource management, business environment, supervision, 2. Protect is the suitable measure for basic structure service, 3 . Detect to find the situation of cybersecurity that might happen, 4 . Respond is the plan, communication, analysis, risk reduction, 5. Recover is the constant practice according to the plan [4].

Ngoc T. Le et al recommended 12 topics of guideline of cloud computing security from the reference of cloud security standard and various maturity models such as ISO, NIST-CSF, SSE-CMM with the objectives to study the maturity models' capability to combine with the security indicator and to recommend cybersecurity of cloud system users (CSCMM) which are in 4 levels - SML0 (Undefined), SML1 (Initiated), SML2 (Managed) and SML3 (Optimized). The highest level is the complete protection [5].

2.3.2 Information Security Forum (ISF) is the group of British information technology security with more than 500 member groups worldwide with the objective to develop standard, handbook, recommendation and practice guideline in the aspect of cybersecurity. ISF has divided threat and how to deal with 3 levels of cybersecurity [6] as shown in Figure 1.

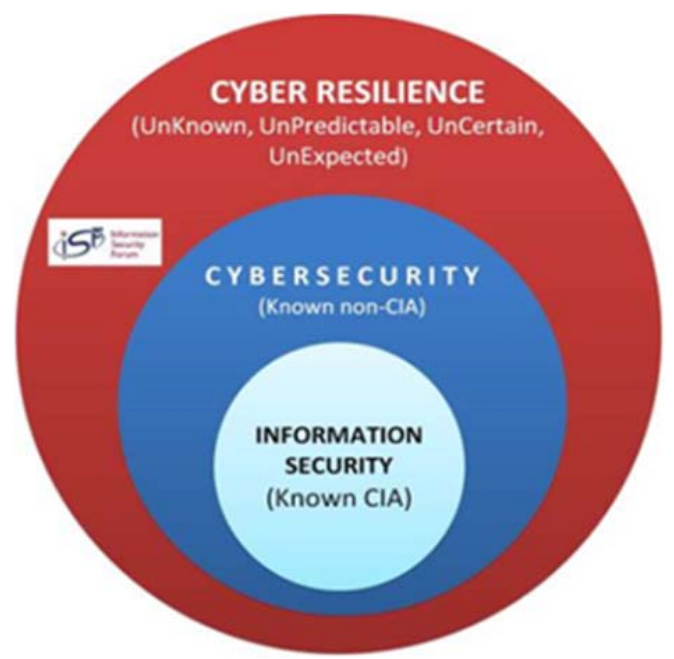

Figure 1. Cybersecurity and Cyber Resilience Model

Information Security or known as CIA presents how to deal with the impact of the CIA which were Confidentiality, Integrity, Availability. Cybersecurity means how to deal with the threat of the higher impact than CIA. Cyber Resilience is the unknown threat management with each shown level.

2.3.3 CIS Critical Security Controls [7], [8] is the solution for crisis security problem by the Center for Internet Security, and it has shown 20 methods to solve the operational problem created to stop threat by referring to the framework of NIST cybersecurity practice.

2.3.4 Cyber Security Resilience Complete SelfAssessment Guide is the handbook to evaluate the security and cyber resilience referred from regulation and standard with the objective to make the organization able to evaluate the determination and component of Cyber Security Resilience on the foundation of good regulation and self-quality management in 7 scopes - Recognize, Define, Measure, Analyze, Improve, Control and Sustain which can be the start of gap analysis to define total effectiveness improving management tool.

2.3.5 The CERT-Resilience Management Model is the basic practice guideline to improve resilience management CERT-RMM [9] composed of 26 process areas, which are divided into 4 topics Engineering, Enterprise Management, Operations and Process Management. Each process acts as the standard criteria identifying the organization ability in the scope of specific process goal. There are 4 specific goals which are: 1. Establish Strategic Objectives, 2. Plan for Operational Resilience, 3. Establish Sponsorship, and 4. Provide Resilience Oversight.

For CERT-RMM (CERT-RMM Capability Maturity Level: MIL) is the measure of high internet security ability by specific Capability Maturity Level indicator divided into 4 ability levels - level 0: incomplete process, level 1: on process, level 2: have the ability to process, level 3: the indication of MIL are MIL 0 partly start, MIL1 preparation, MIL2 proceed according to plan, MIL4 evaluation/assessment, MIL5 indication' / follow up, MIL6 communication.

2.3.6 CMMI is the measurement standard of information project management which is one of the projects invented in 1987 as Capability Maturity Model (CMM) by Software Engineering Institute (SEI). The institute is in Carnegie-Mellon University established and financially supported by United States Department of Defense in order to identify the check list to software production. This model receives the report from International Business Machines (IBM) Corporation, Philip Crosby and W. Edwards Deming on the quality guarantee and country defense application. After that CMM [10] is widely used with several revision leading to the development of CMMI (Integrated is added). CMMI is widely accepted as high standard in order to guarantee software within production company, including the development and effective management. Current version of CMMI ${ }^{\circledR}$ is version 2.0 (December 2018). There are 3 types of CMMI Product Suit set according to various process improvement demands and each process composition are giving the guideline to improve the interested 
scope such as acquisition (ACQ), development (DEV) and service (SVC) [11].

CMMI determines resilience capability maturity level from the ability of risk management which is the important foundation of resilience according to these assessment topics 1. Ensure Governance Framework, 2. Establish Risk Management, 3. Identify and Manage Risks, 4. Ensure Risk Mitigation, 5. Ensure Risk Detection, 6. Ensure Risk Response, and 7. Ensure Resilience. CMMI Appraisal then is the Standard CMMI Appraisal Method for Process Improvement (SCAMPI) employing the assessment principal called PII or Practice Implementation Indicator saying that the assessment from witness object or evidence which is the result of action, but it is not evaluated by having the company perform all software process CMMI assessment by SCAMPI, which can be divided into 3 types [12] 1. Class A - Authorized Lead Appraiser from only SEI. The appraiser is called Appraisal Team Members (ATM) with at least 4 members including lead appraiser. If meets the assessment, the organization will get Maturity Level rating or Capability Level rating.

SCAMPI A is the only assessment with rating. It is noticeable that CMMI uses the word get "rated" not get "certified". Result of validity period is 3 years. 2 . Class B - is usually for process reviews or audits or rehearse for SCAMPI A rating. There are at least 2 appraiser members. The leader can be those who get trained on SCAMPI B\&C Team Leader or the experienced. 3 Class $\mathrm{C}-$ is usually to review the informal process which is called Gap Analysis to be able to determine the goal of capability maturity / suitable capability with the current organization process including knowing work load that need to be improved if it is in accordance with duration plan. There can be only one appraiser who passes the training of SCAMPI B\&C Team Leader or the experienced.

\section{Method}

The authors have shown the thorough 13 steps of research methodology as in Figure 2.

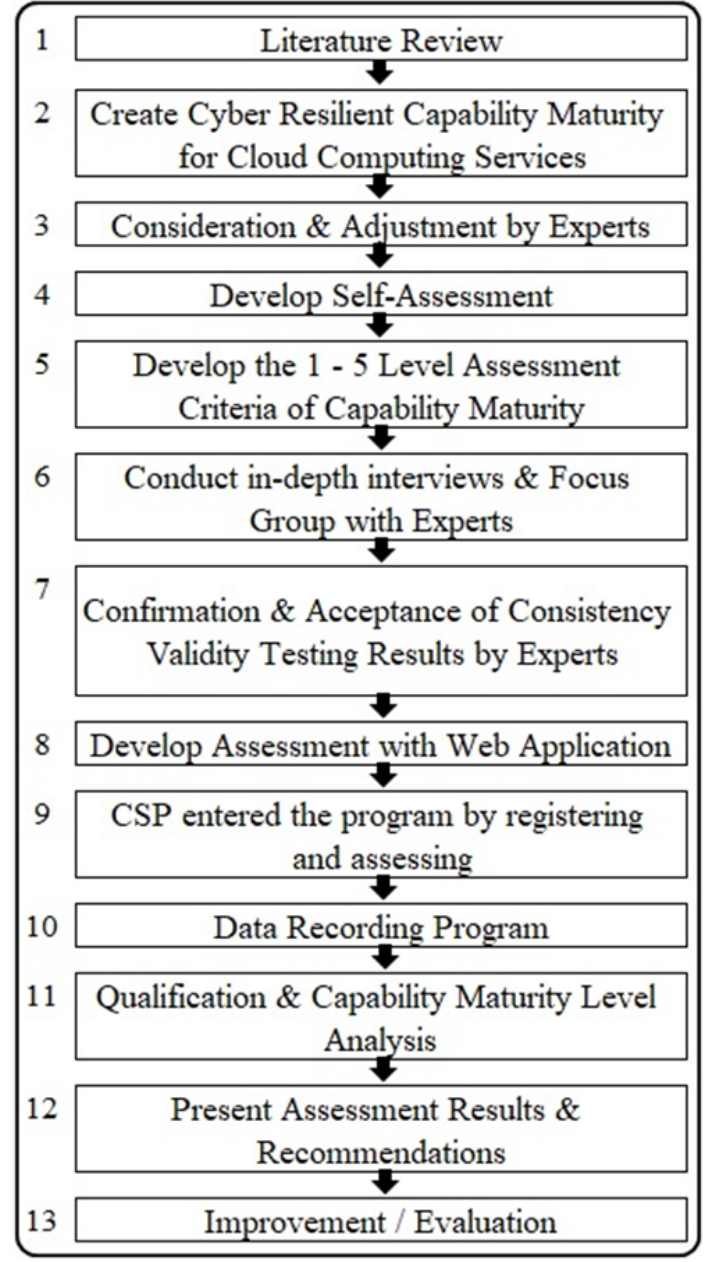

Figure 2. Methodology Framework 


\section{Research Results}

\subsection{Cyber Resilient Capability Maturity Model for Cloud Computing Services}

The authors employed the practice guideline on cybersecurity from NIST CSF and adjusted it to be the practice on cyber resilience framework. The guidelines and regulations were studied and referenced in order to make trustworthiness for the resilience which the authors took on Privacy, Partner/Supplier Agreement (Standards, Laws \& Rules), Detective Evaluation, Predictive, Communications \& Awareness, Education, Dependability Planning, Communications \& Literacy, Cyber Governance, Reliability, Availability, Safety and Maintainability to support and to be the plan to indicate the dependability on reliability to cloud system. It needed the determination of fail, false and error that might happen in cloud computing services. The author's concept will have strength, defensed the threat in term of smart communication when threat happened in service system, knowledgeable communication as the core component for people, process, and technology.

The authors found that from the review of several standards, part of the mistakes or lost was from the ignorance community. It was unsuitable without understanding community and without intelligence. For the improvement in the context of dependability meant the improvement of method, process relating to the better service. Governance in the context of dependability meant the control on people, process and technology as the practice guideline to create confidence on the resistance or cloud services cyber resilience. It could be concluded to be 6 practice guidelines topics with 35 frameworks as shown in Figure 6, and to improve the cyber resilient capability maturity model for Cloud computing services as in Figure 3.

\begin{tabular}{|c|c|c|c|c|c|}
\hline \multicolumn{6}{|c|}{ Cyber Resilient Model for Cloud Computing Services } \\
\hline IDENTIFY & PROTECT & DETECT & RESPOND & RECOVER & DEPENDABILIT \\
\hline Asset Management & \begin{tabular}{|c|} 
Identity \\
Managemeat, \\
Authentication and \\
Access Control \\
\end{tabular} & $\begin{array}{l}\text { Anomalies and } \\
\text { Events }\end{array}$ & Response Planning & Recovery Planning & $\begin{array}{c}\text { Dependability } \\
\text { Planning }\end{array}$ \\
\hline $\begin{array}{c}\text { Business } \\
\text { Environment }\end{array}$ & $\begin{array}{l}\text { Awareness and } \\
\text { Training }\end{array}$ & $\begin{array}{c}\text { Security } \\
\text { Continuous } \\
\text { Monitoring } \\
\end{array}$ & Communications & Improvement & $\begin{array}{c}\text { Communications } \\
\& \text { Literacy }\end{array}$ \\
\hline Governance & Data Security & $\begin{array}{l}\text { Detection } \\
\text { Processes }\end{array}$ & Analysis & $\begin{array}{c}\text { Communications } \\
\& \text { Awareness }\end{array}$ & Cyber Governance \\
\hline Risk Assessment & \begin{tabular}{|c|} 
Info Protection \\
Processes and \\
Procedures \\
\end{tabular} & $\begin{array}{l}\text { Detective } \\
\text { Evaluation }\end{array}$ & Predictive & Education & Reliablity \\
\hline \begin{tabular}{|c|}
$\begin{array}{c}\text { Risk Management } \\
\text { Strategy }\end{array}$ \\
\end{tabular} & Maintenance & & Mitigation & & Avaliability \\
\hline \begin{tabular}{|c|} 
Supply Chain Risk \\
Management
\end{tabular} & $\begin{array}{l}\text { Protective } \\
\text { Technology }\end{array}$ & & Improvements & & Safety \\
\hline Privacy & \begin{tabular}{|c|} 
Partner \& Supplier \\
Agreement \\
(Standards, Lawss \\
\& Rules) \\
\end{tabular} & & & & Maintainability \\
\hline
\end{tabular}

Figure 3. Cyber Resilient Model for Cloud Computing Services
The authors has presented the framework of the cyber resilient capability maturity model for cloud computing services for the analyzation and consideration of the possibility to arrange the inquiry determination in Self-Assessment [13] about Cloud Resilient Self-Assessment Questionnaire in the framework to be the indicator of cyber resilient capability maturity model for cloud computing services. The expert had assessed the suitability of Cloud Resilient Self-Assessment framework and recommended the proper improvement as shown in 35 frameworks and had developed 145 indicators development for resilience evaluation for cloud computing service from 35 frameworks above.

\subsection{Capability Maturity 1-5 Level Arrangement}

For the identification of cyber capability maturity model for cloud computing services defied 5 levels level 1 was the initial without the service support standard, but there was the policy defying or plan initial and the written record or organizational document. Level 2 was the interest in bringing standard relating with the service to be managed according to level 1 and added internal or external organization communication, the practice of policy or plan with inspection. Level 3 was the level that the organization defined because they worked according to the standard with the inspection and inspecting document and specific responsibility. Level 4 is optimized by statistic or recording statistic from threat incident to evaluate and improve. Level 5 is resilient that was the level defying cloud computing system resistance and able to return to Cyber Resilience because of the regular maintenance including inspecting documents. The cyber resilient capability maturity model is showing in Table 1.

For Cloud computing service, there were component and internal indicators showing the ability of Cloud service providers in term of threat responding measure and cyber resilience capability. The score gained from the assessment as organization representor passed all 35 frameworks showing cyber resilient capability maturity as followed:

Capability maturity indicator 1-2 was in level 1 , Capability maturity indicator 1-5 was in level 2, Capability maturity indicator 1-7 was in level 3, Capability maturity indicator 1-8 was in level 4 and Capability maturity indicator 1-10 was in level 5 .

\subsection{In-depth interview and Focus Group}

The in-depth interview with the expert towards the way defining the cyber resilient capability maturity model for cloud computing services was done by the kindly approval of 3 branches experts which were 8 
cloud computing experts, 7 cybersecurity experts and 4 capability maturity experts. There were in total 19 experts to consider and give thorough information what the authors had operated about the suitability and acceptance on what the authors studied. The result of the suitability and accordance of guideline determining the capability maturity and cyber resilience for cloud computing system that the authors used Content Analysis by the expert from the in-depth analysis [14] is giving the practice guideline from the experience of the experts in the aspect of the creation of cyber resilience for cloud computing system. The authors gained practice framework, indication tools with the criteria for cyber resilient capability maturity model for cloud computing services together with the result from in-depth interview by content analysis, and found that it was suitable with the model, equipment, capability maturity and criteria for cyber resilient capability maturity model for cloud computing services from the expert with the suitability with every determined guideline.

Table 1. The cyber resilient capability maturity model
The result of guideline confirmation of model, equipment, capability maturity and criteria for cyber resilient capability maturity model [15] for cloud computing services is obtained from conversation with focus group from the expert in the issue that needed confirmation for the more concrete research result. The authors then arranged the conversation with the approval from 6 experts to inspect and confirm the guideline presented in the research.

When used in the research, the organization of cloud service provider needed to have the working process on 6 aspects of cybersecurity composing 35 frameworks with 10 steps of capability maturity indicator which were: 1 . Plan management or policy determination, 2. Written policy record, 3. Internal and external organization communication, 4. Taking into practice, 5. Inspection and supervision, 6. Inspecting document, 7. Specific responsible person or organization, 8. The statistic used to record important data, 9. Constant evaluation and improvement, and 10. Document reporting every working process. The authors had evaluated to decide the selection of evaluation on the company with more than 1 evaluators using Analytic Hierarchy Process (AHP) which was the process effectively deciding in term of hierarchical chart, and then defined the value of comparing analysis of several factors. We took those numbers to calculate to factors and choices with the highest importance level as shown in Table 2.

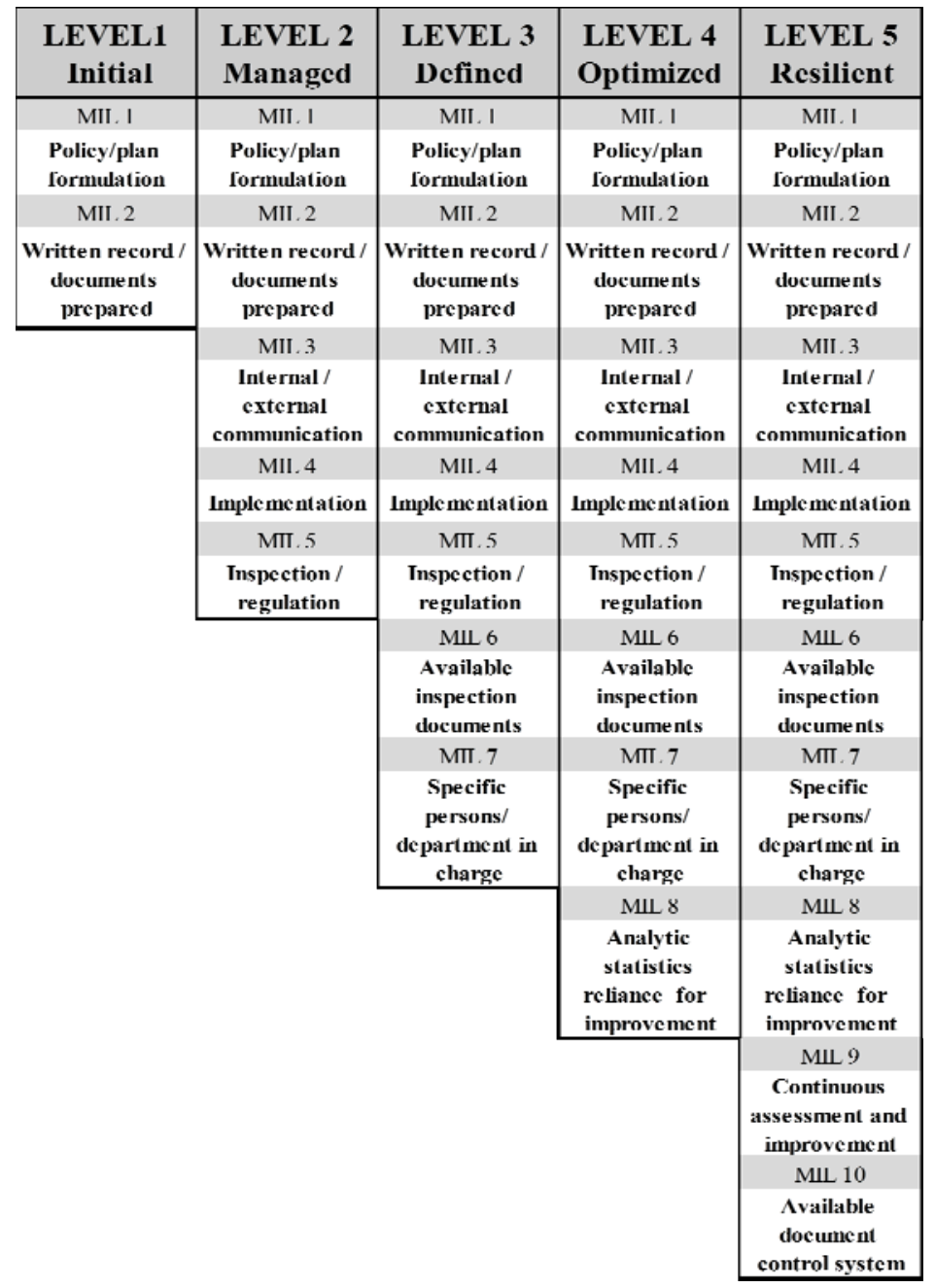


Table 2. The result analysis and maturity level scale

\begin{tabular}{|c|c|c|c|c|c|c|c|c|c|c|c|c|c|c|c|c|}
\hline revernows & \multicolumn{4}{|c|}{ NEY processes } & QT & Yes & $\begin{array}{c}1 \\
\text { nas }\end{array}$ & ${ }^{2}$ & 3 & 4 & $\stackrel{5}{\text { Cand }}$ & ${ }^{6}$ & c & 8 & Aet & Mt \\
\hline mestry & tows & \multicolumn{3}{|c|}{ Anet Stasagram } & 6 & 1 & 1 & 1 & 1 & 1 & 1 & 1 & 1 & 1 & 1 & 1 \\
\hline \multirow{6}{*}{$\begin{array}{l}\text { Mere sen: } \\
\text { sset }\end{array}$} & Dast & \multicolumn{3}{|c|}{ 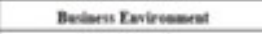 } & $s$ & 1 & 1 & 1 & 1 & 1 & 1 & 1 & 1 & 1 & 1 & 1 \\
\hline & D.GV & \multicolumn{3}{|c|}{ Cevernaser } & 4 & 1 & 1 & 1 & 1 & 1 & 1 & 1 & 1 & 1 & 1 & 1 \\
\hline & IDRA & \multicolumn{3}{|c|}{ Batastenserat } & 6 & f & 1 & 1 & 1 & 1 & 1 & 1 & 1 & 1 & 1 & 1 \\
\hline & tonst & \multicolumn{3}{|c|}{ Riad Mtanagenent Strateg } & 3 & t & 1 & 1 & 1 & 1 & 1 & 1 & 1 & 1 & 1 & 1 \\
\hline & mse & \multicolumn{3}{|c|}{ 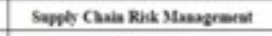 } & 7 & 1 & 1 & 1 & 1 & 1 & 1 & 1 & 1 & 1 & 1 & I \\
\hline & $\tan$ & \multicolumn{3}{|c|}{ Prirsy } & 7 & 1 & 1 & 1 & 1 & 1 & 1 & 1 & 1 & 1 & 1 & 1 \\
\hline \multirow{2}{*}{ rexcroess } & \multirow{2}{*}{\multicolumn{4}{|c|}{ KXY PROCESSES }} & & & 1 & 2 & 3 & 4 & $s$ & 6 & 7 & 8 & , & 10 \\
\hline & & & & & QT & Ves & nea & Mas & $D_{0}$ & Do & Conk & Carek & Coes & set & Aet & set \\
\hline Photret & PEAC & \multicolumn{3}{|c|}{ 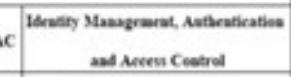 } & 6 & 1 & 1 & 1 & 1 & 1 & 1 & 1 & 1 & 1 & 1 & 1 \\
\hline \multirow{6}{*}{$\begin{array}{l}\text { Mere sess } \\
\text { net }\end{array}$} & FR.AT & \multicolumn{3}{|c|}{ Avarvarus sad Truibibs } & 5 & t & 1 & 1 & 1 & 1 & 1 & $t$ & 1 & 1 & 1 & 1 \\
\hline & PR.DS & \multicolumn{3}{|c|}{ Data Seraritily } & 6 & r & 1 & 1 & 1 & 1 & 1 & 1 & 1 & 1 & 1 & 1 \\
\hline & FR.IP & \multicolumn{3}{|c|}{ 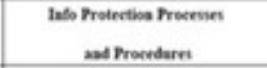 } & 9 & 1 & 1 & 1 & 1 & 1 & 1 & 1 & 1 & 1 & 1 & 1 \\
\hline & resu & \multicolumn{3}{|c|}{ Maibienaser } & 2 & 1 & 1 & 1 & 1 & 1 & 1 & 1 & 1 & 1 & 1 & 1 \\
\hline & FERT & & otertive Ied & wow & 4 & t & 1 & 1 & 1 & 1 & 1 & 1 & 1 & 1 & 1 & 1 \\
\hline & TRKA & $\begin{aligned} \text { Partart } \\
\text { Seand }\end{aligned}$ & 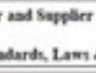 & $\begin{array}{l}\text { Agrerement } \\
\text { Enalei) }\end{array}$ & 3 & $t$ & 1 & 1 & 1 & 1 & 1 & 1 & 1 & 1 & 1 & 1 \\
\hline nxcrnoess & & KEY : & PKOCESsE & & QT & Yes & $\begin{array}{c}1 \\
\text { nis }\end{array}$ & $\begin{array}{c}2 \\
\text { nas }\end{array}$ & 3 & $\dot{1}$ & cisk & 6 & $\begin{array}{c}7 \\
\text { Conk }\end{array}$ & set & set & int \\
\hline DETECT & DEA & & anables and & treatis & 4 & 1 & 1 & 1 & 1 & 1 & 1 & 1 & 1 & 1 & 1 & 1 \\
\hline Mere ses: & Decul & Sererenty & Contianos: & Asonituriag & 7 & t & 1 & 1 & 1 & 1 & 1 & 1 & 1 & 1 & 1 & 1 \\
\hline $20 \%$ & DE DP & & Detertion Pros & men & 4 & 1 & 1 & 1 & 1 & 1 & I & 1 & 1 & 1 & 1 & 1 \\
\hline & DEDE & & etertine Erat. & uttion & 5 & 1 & 1 & 1 & 1 & 1 & 1 & 1 & 1 & 1 & 1 & 1 \\
\hline rexcnoss & & KXY: & reocrsis: & & QT & Vet & $\stackrel{1}{\text { Has }}$ & ${ }_{\text {nia }}^{2}$ & Do & Do & $\stackrel{5}{\text { carek }}$ & ched & cirek & set & ats & 10 \\
\hline Restond & RSnos & & Rrspene Mas & $\Rightarrow$ & 1 & 1 & 1 & 1 & 1 & 1 & 1 & $\bar{I}$ & 1 & 1 & 1 & 1 \\
\hline Share sos: & Rsco & & Cresenotian & & 4 & 1 & 1 & 1 & 1 & 1 & 1 & 1 & 1 & 1 & 1 & 1 \\
\hline $170 \mathrm{TT}$ & Rous & & Analyon & & 4 & 1 & 1 & 1 & 1 & 1 & 1 & 1 & 1 & 1 & 1 & 1 \\
\hline Q & RSW & & Preblictere & & 4 & 1 & 1 & 1 & 1 & 1 & 1 & 1 & 1 & 1 & 1 & 1 \\
\hline & essa & & Marizabive & & 2 & 1 & 1 & 1 & 1 & 1 & 1 & 1 & 1 & 1 & 1 & 1 \\
\hline & RS.PM & & Ineperveras & & 2 & 1 & 1 & 1 & 1 & 1 & 1 & 1 & 1 & 1 & 1 & 1 \\
\hline resctioss & & KEY: & Focesses & & QT & Yes & $\begin{array}{c}1 \\
\text { has }\end{array}$ & $\begin{array}{c}2 \\
\text { nus }\end{array}$ & Do & $\stackrel{4}{D}$ & $\stackrel{5}{c a n k}$ & $\stackrel{6}{\cos }$ & $\begin{array}{c}7 \\
\text { CMek } \\
\end{array}$ & set & Ad & Aet \\
\hline RECONER & RCER & & Reverery Nas & alay & 1 & 1 & 1 & 1 & 1 & 1 & 1 & 1 & 1 & 1 & 1 & 1 \\
\hline Shore sos: & RCBI & & Ieprovent & & 2 & 1 & 1 & 1 & 1 & 4 & 1 & 1 & 1 & 1 & 1 & i \\
\hline not & RCCA & Comen & akratieat $k$. & Neareares & ? & 1 & 1 & 1 & 1 & 1 & 1 & 1 & 1 & 1 & 1 & 1 \\
\hline & RCED & & Edecatioe & & 2 & 1 & 1 & 1 & 1 & 1 & 1 & 1 & 1 & 1 & 1 & 1 \\
\hline rexcnoss & & sxy: & reocesse & & QT & Ves & Thas & ${ }^{2}$ & Do & $\dot{4}$ & $\stackrel{5}{\text { Canck }}$ & Cand & $\begin{array}{c}7 \\
\text { Carek }\end{array}$ & $\begin{array}{c}3 \\
\text { Act }\end{array}$ & Ant & Aet \\
\hline DEREDAKHI & DPDP & & pedatery $\mathbf{n}$ & anabs & 1 & 1 & 1 & 1 & 1 & 1 & 1 & 1 & 1 & 1 & 1 & 1 \\
\hline Store 50 s. & DPCL & Cons & Devirutios \& 8 & Lerragy & 3 & 1 & 1 & 1 & 1 & 1 & 1 & 1 & 1 & 1 & 1 & 1 \\
\hline & DPCG & & Gter Goren & ase & 4 & 1 & 1 & 1 & 1 & 1 & 1 & 1 & 1 & 1 & 1 & 1 \\
\hline $21 \mathrm{Q1}$ & DPST & & Retisuating & & 3 & 1 & 1 & 1 & 1 & 1 & 1 & 1 & 1 & 1 & 1 & 1 \\
\hline & DPAT & & Aralabater & & 5 & 1 & 1 & 1 & 1 & 1 & 1 & 1 & 1 & 1 & 1 & 1 \\
\hline & DEST & & Saterty & & 3 & 1 & 1 & 1 & 1 & 1 & $t$ & 1 & 1 & 1 & 1 & 1 \\
\hline & DPSIr & & 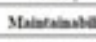 & & 2 & 1 & 1 & 1 & 1 & 1 & 1 & 1 & 1 & 1 & 1 & 1 \\
\hline & & & Teesal Serebl & & 145 & & 2 & & & nas & & 1.01 & 15 & 1.160 & & \\
\hline Level Scale L & evel 1 & Level 2 & Level 3 & Level 4 & Leve & & Len & & & & & & & & & \\
\hline $100 \%$ & 290 & 725 & 1,015 & 1,160 & 1,45 & & & & & & Lmels & & & & & \\
\hline $80 \%$ Pass & 232 & 580 & & & & & & & & & & Leat 4 & & & & \\
\hline $80 \%$ Pass & 232 & 580 & 812 & 1,016 & 1,16 & & & & & & & & & Lnets & & \\
\hline
\end{tabular}

\subsection{The result of Develop Self-Assessment Program for CSP}

From the framework of cyber resilience and capability maturity cyber resilience for the authors used to be the issue in creating evaluation form and develops application referring from software development cycle in 7 steps: 1 . Understanding the problem, 2. Study the possibility, 3. Analysis, 4. Design, 5. System development, 6. Usage, and 7. Maintenance, which is the total image of application for Self-Assessment Program for CSP.

\subsection{CSP for Self-Assessment and Data Collection Program}

The access to evaluation application level of capability in maintaining information security and cyber resilience for cloud computing services, the users received username and password to the system and evaluated in each topic, users can access by IP http://183.88.230.105:8088 as shown in the first page of Figure 4. 


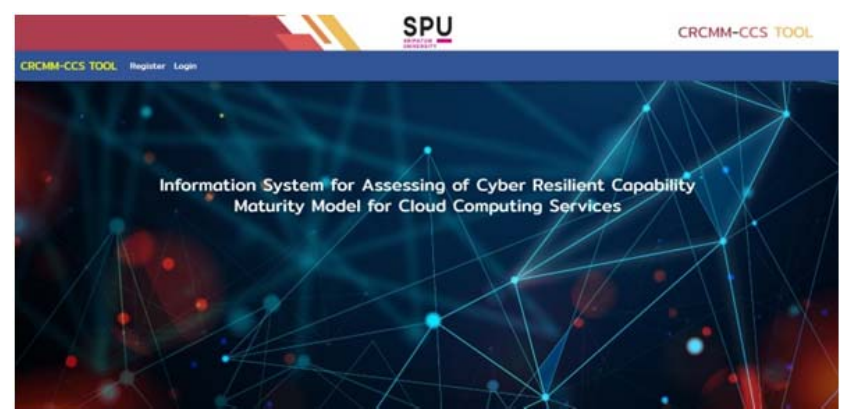

Figure 4. CSCMM-CCS Tool Evaluation Web Application

The authors developed the found result to be the evaluation of cyber resilient capability maturity model for cloud computing services of Cloud Service Company by creating application and tested with 2 companies. The authors asked each company to have 3 appraisers and used Analytic Hierarchy Process (AHP) to decide evaluation result. The first appraiser was VP of Information Technology. The second appraiser was IT Manager / IT Auditor. The third appraiser was IT Administrator / IT Support showing structure of Analytic Hierarchy. [16]

Table 3. Maturity score calculating method

\begin{tabular}{|c|c|c|c|c|c|c|c|c|}
\hline \multicolumn{2}{|c|}{ Maturity level estimated } & \multirow{2}{*}{$\begin{array}{c}\text { ID } \\
280\end{array}$} & \multirow{2}{*}{$\begin{array}{c}\text { PR } \\
370\end{array}$} & \multirow{2}{*}{$\begin{array}{l}\text { DE } \\
200\end{array}$} & \multirow{2}{*}{$\begin{array}{c}\text { RS } \\
170\end{array}$} & \multirow{2}{*}{$\begin{array}{c}\text { RC } \\
120\end{array}$} & \multirow{2}{*}{$\begin{array}{l}\text { DP } \\
210\end{array}$} & \multirow{2}{*}{$\begin{array}{l}\text { Total } \\
1,450\end{array}$} \\
\hline $1 \rightarrow$ & Full score & & & & & & & \\
\hline \multirow[t]{5}{*}{$2 \rightarrow$} & Factor loading & $23 \%$ & $21 \%$ & $16 \%$ & $14 \%$ & $11 \%$ & $15 \%$ & $100 \%$ \\
\hline & Assessor 1 & 238 & 167 & 135 & 75 & 73 & 177 & 865 \\
\hline & Assessor 2 & 252 & 218 & 120 & 105 & 82 & 160 & 937 \\
\hline & Assessor 3 & 233 & 184 & 108 & 66 & 64 & 180 & 835 \\
\hline & Total score & 723 & 569 & 363 & 246 & 219 & 517 & 2,637 \\
\hline \multirow[t]{2}{*}{$3 \longrightarrow$} & Average & 241 & 190 & 121 & 82 & 73 & 172 & 879 \\
\hline & Pass Score & 304 & 185 & 100 & 85 & 60 & 105 & \\
\hline \multicolumn{2}{|c|}{ Score missed in each category } & -63 & - & - & -3 & - & - & \\
\hline \multicolumn{2}{|c|}{ Pass/Fail } & Fail & Pass & Pass & Fail & Pass & Pass & \\
\hline
\end{tabular}

From Table 3, the system would not calculate capability maturity since the program was set the criteria of minimum score in Identify (ID) $=80$, and other 5 topics $=50 \%$ which were Protect $(\mathrm{PR})$, Detect (DE), Respond (RS), Recover (RC) and Dependability (DP).

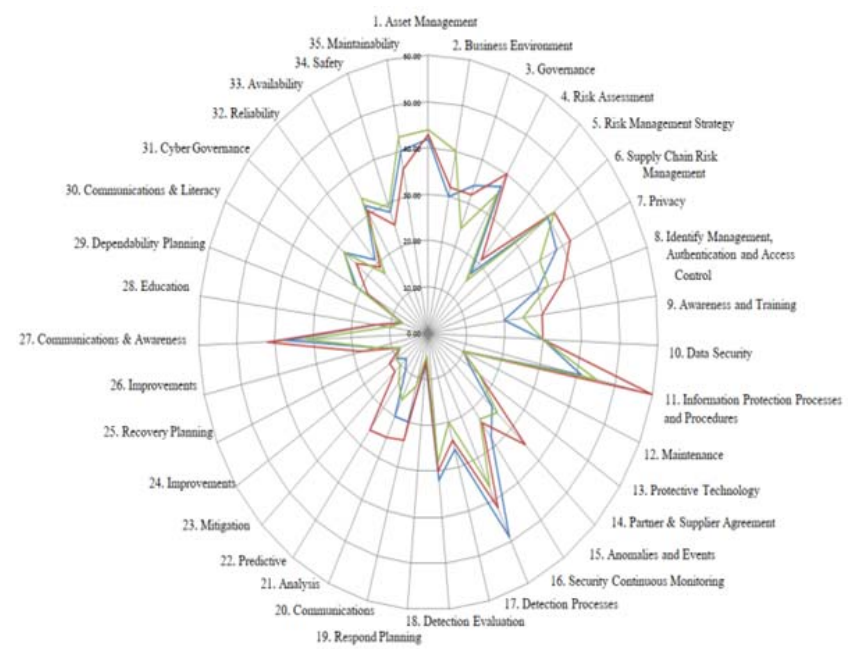

Figure 5. CSP Evaluation Results Graph
The result of information evaluation on various persons by AHP showed the service providers what it passed the criteria or not with the failure on which maturity indicator level. Moreover, it showed the risk level of cybersecurity aspect in Cloud computing service system helping the concrete practice.

\section{Conclusion}

In this paper, we develop cyber resilient model and cyber resilient capability maturity model. We present self-assessment for cyber resilient capability maturity model of cloud computing services. Finally, we conclude that:

1) For the result, the concept and evaluating tools were found showing more guideline [17] to apply the cyber resilience and cloud computing services. It was able to bring into actual practice from the experience and research result presented; it was suitable for the organization and cloud service providers to use the cyber resilient capability maturity model in the organization.

2) Good indicators needed to create inspiration leading to successful organization goal, and it should not be too hard or too vague unable to evaluate because the important thing was to achieve the objective. If the indicator determination had too high standard it would cause the opposite damage without any inspiration for employees or departments to cooperate in order to achieve the objective as what the authors had presented 10 indicators. When considered each of them, it was found that the component of system development cycle is concept from PDCA of ISO27001 offered by the authors for the tool which is to be constantly improved within working process and control working quality.[18]

The result of this research became the guideline for cloud services organizational development or specific aspect or business group in order to develop selfassessment system and effectively apply in their own organization. 


\section{Acknowledgements}

This work is supported by the National Research Council of Thailand through the School of Information Technology, Sripatum University, Bangkok, Thailand.

\section{References}

[1]. Roberts, E., Farrington, J., \& Skerratt, S. (2015). Evaluating new digital technologies through a framework of resilience. Scottish Geographical Journal, 131(3-4), 253-264.

[2]. Engineering Institute of Thailand Under H.M. The King's Patronage. Cloud Service Operation Standard (EIT. 102002-18). The general public issue. 2018.

[3]. Surbakti, H. (2014). Cobit 4.1: A maturity level framework for measurement of information system performance (case study: academic bureau at universitas respati yogyakarta). International Journal of Engineering Research \& Technology (IJERT), 3(8), 999-1004.

[4]. Barrett, M. P. (2018). Framework for improving critical infrastructure cybersecurity. National Institute of Standards and Technology, Gaithersburg, MD, USA, Tech. Rep.

[5]. Ngoc T. Le and Doan B. Hoang. (2017). Capability maturity model and metrics framework for cyber cloud security. Scalable Computing: Practice and Experience, 18(4), 277-290.

[6]. Hugh Boyes. (2015). Cybersecurity and CyberResilient Supply Chains. The Technology Innovation Management Review, 4, 28-34.

[7]. CIS Security Metrics - Quick Start Guide v1.0.0, The Center for Internet Security, Nov. 2010.

[8]. The CIS Critical Security Controls for Effective Cyber Defense Version 6.1. [Online]. Available from: https://www.cisecurity.org/controls/. [Accessed: 20- January-2020].

[9]. Stewart, K., Allen, J., Dorofee, A., Valdez, M., \& Young, L. (2015). Defining a Maturity Scale for Governing Operational Resilience (No. CMU/SEI2015-TN-004). Carnegie-Mellon Univ Pittsburgh Pa Pittsburgh United States.
[10]. Adler, R. M. (2013, November). A dynamic capability maturity model for improving cyber security. In 2013 IEEE International Conference on Technologies for Homeland Security (HST) (pp. 230235). IEEE.

[11]. Luiz Sergio Placido, Renata Moeria, Mauricio Souza and Alexandre Marcos Lins de Vasconcelos. (2016). A qualitative analysis of the adherence between the Information Technology Solution Acquisition Guide. In Proceedings of 28th International Conference on Software Engineering \& Knowledge Engineering (SEKE 2016), 653-654.

[12]. Habib, S. M., Varadharajan, V., \& Mühlhäuser, M. (2013, July). A trust-aware framework for evaluating security controls of service providers in cloud marketplaces. In 2013 12th IEEE International Conference on Trust, Security and Privacy in Computing and Communications (pp. 459-468). IEEE.

[13]. Ahmad, A. (2016). A cyber exercise post assessment framework: In Malaysia perspectives (Doctoral dissertation, University of Glasgow).

[14]. Duarte, A., \& da Silva, M. M. (2013, June). Cloud maturity model. In 2013 IEEE Sixth International Conference on Cloud Computing (pp. 606-613). IEEE.

[15]. Ghaffari, F., \& Arabsorkhi, A. (2018, December). A New Adaptive Cyber-security Capability Maturity Model. In 2018 9th International Symposium on Telecommunications (IST) (pp. 298-304). IEEE.

[16]. Hwang, K., Kulkareni, S., \& Hu, Y. (2009, December). Cloud security with virtualized defense and reputation-based trust mangement. In 2009 Eighth IEEE International Conference on Dependable, Autonomic and Secure Computing (pp. 717-722). IEEE.

[17]. Marcon, A. L., Santin, A. O., Stihler, M., \& Bachtold, J. (2013). A \$( $\mid \mathrm{rm} U \mathrm{UCON}\{\mathrm{ABC}\}) \$$ Resilient Authorization Evaluation for Cloud Computing. IEEE Transactions on Parallel and Distributed Systems, 25(2), 457-467.

[18]. Miloslavskaya, N. (2018). Developing a network security intelligence center. Procedia computer science, 145, 359-364. 